\title{
Resituating Aotearoa New Zealand mental health legislation in the context of social and occupational justice
}

\author{
Kirk D. Reed ${ }^{1}$ and Brian Field ${ }^{2}$
}

\begin{abstract}
INTRODUCTION: Social work and occupational therapy mental health practitioners face a range of tensions in relation to statutory obligations in the context of maintaining a focus on the ideals of social or occupational justice.

APPROACH: The aim of this article is to highlight some of the complexities for social work and occupational therapy practitioners in an environment dominated by a medico-legal worldview. Those complexities include creating and maintaining a therapeutic relationship, adhering to legal obligations; and staying focused on professional values and beliefs. We have explored notions of social justice and occupational justice and undertaken a descriptive chronological review of Aotearoa New Zealand mental health legislation.
\end{abstract}

IMPLICATIONS: We have provided an insight in to some of the key factors that have influenced the development of mental health legislation in this country in relation to social and occupational justice. We have considered how the medico-legal worldview influences staying true to the notions of social and occupational justice and have made suggestions for change relative to practice and the legislation.

KEYWORDS: mental health; mental health legislation; Aotearoa New Zealand; social justice; occupational justice

Social work and occupational therapy practitioners in Aotearoa New Zealand mental health services face a complex practice environment. The practice environment is underpinned by a historical legal framework that is often in conflict with issues of social justice and occupational justice. The aim of this article is to explore the notions of social and occupational justice, provide a descriptive chronological overview of New Zealand's mental health legislation and consider potential social and occupational justice issues in relation to practice. Our position is that social work and occupational therapy practitioners are often faced with the challenge of advocating for service users/tangata whai ora in the context of a mental health system strongly influenced by dominant medical and legal worldviews. This context often results in a form of social control over the population which is in conflict with a recovery paradigm. The term "recovery" for people with mental health issues is not new. McCranie (2011) highlights notions of recovery can be traced back over 200 years to the work of Phillippe Pinel in the Paris asylums. In more recent times, the recovery paradigm has emerged from within the survivor movement and the work of Patricia Deegan (1988) who wrote an account of her illness and recovery experiences and argued
${ }^{1}$ Auckland University of Technology, New Zealand

${ }^{2}$ Midcentral District Health Board, New Zealand
AOTEAROA NEW ZEALAND SOCIAL WORK 29(3), 55-65.

CORRESPONDENCE TO: Kirk D. Reed kirk.reed@aut.ac.nz 
that recovery is different from psychosocial/ psychiatric rehabilitation. From an academic perspective, William Anthony (1991) from the Boston University Centre for Psychiatric Rehabilitation outlined a vision of recovery that continues to guide service delivery. The work of Rapp and Goscha (2012) in the 1990s who were early advocates of the recovery approach, developed the strengths model. The strengths model is a widely used paradigm of practice that embodies the recovery approach. In Aotearoa New Zealand, the recovery paradigm provides an overarching framework to guide mental health service planning and delivery. The recovery approach in the Aotearoa New Zealand landscape is defined as "creating a meaningful self-directed life regardless of challenges faced, that includes building resilience, having aspirations and the achievement of these" (Te Pou, 2014, p. 5). Notions of recovery are embedded in New Zealand documents such as the "Blueprint II: How Things Need to Be" (Mental Health Commission, 2012) and "Rising to the Challenge: The Mental Health and Addictions Service Development Plan 20122017" (Ministry of Health, 2012). Recovery places a premium on self-determination, human rights and empowerment. While the recovery approach appears core to mental health service delivery, there is the potential for disagreement when the hegemony of the legal and medical worldviews and the recovery approach cross paths. This is particularly the case when a person is deemed in need of compulsory assessment and treatment or when the focus of professions such as social work and occupational therapy differ from the dominant worldview.

The notion of occupational justice is relatively new and is focused on fairness, equity and enabling participation in occupation for health and quality of life (Stadnyk, Townsend, \& Wilcock, 2010; Wilcock, 2006). From an occupational therapy perspective, occupations are meaningful to the individual and valued by a culture and include "everything people do to occupy themselves, including looking after themselves (self-care), enjoying life (leisure), and contributing to the social and economic fabric of their communities (productivity)" (Canadian Association of Occupational Therapists, 2007, p. 181). Situations where individuals are confronted with socio-political barriers that impede participation in occupations are considered instances of occupational injustice (Stadnyk et al., 2010). On the other hand, social justice as a notion, has existed in the western world for much longer and can be traced back to ideas from Plato, Aristotle and Socrates; it is seen as one of the key components of classical moral philosophy (Hamedi, 2014). Social justice, in its broadest sense, concentrates on the social nature of humans in the context of society and social relationships. Social justice has a major role to play in equity of access to the necessities of life in order for people to be functioning fully: it cannot be separated from human rights (Durocher, Rappolt, \& Gibson, 2014). Situations where individuals do not receive equal access to resources and opportunities are considered instances of social injustice. Social justice and occupational justice are seen as complementary and have the concept of equity in common (Wilcock \& Townsend, 2000), along with the need for just governance that encompasses "fairness, empowerment and equitable access to resources, and sharing of rights and responsibilities" (Wilcock, 2006, p. 4). A significant point of difference is that occupational justice places "emphasis on the importance of enabling participation in meaningful occupation" (Durocher et al., 2014, p. 421). The ideas of social and occupational justice inform social work and occupational therapy practice respectively, but are likely to be in contrast to dominant medico-legal views. In addition, practitioners are faced with the tension of being "agents of the state" in the sense of likely being employed by a state funded organisation that brings the expectation of operating within legal frameworks. This may contrast with profession-specific views of advocating for, and on behalf of, service users/tangata 
whaiora in access to resources, fairness, empowerment and participation in society.

The development of legislation in the mental health arena in Aotearoa New Zealand has been influenced by a range of factors that include: the dominance of western legal viewpoints, national and international socio-political trends, advances in medical treatment, government reforms, financial constraints, professionalisation of the mental health workforce and the rise of the consumer movement. In addition, Te Tiriti o Waitangi ${ }^{1}$ has gained wider recognition and acknowledgment in the health sector since 1992 when it was first acknowledged in the health context by the then Minister of Health, Jenny Shipley (Reed, 2006). This has resulted in a significant move toward viewing health as a combination of social, cultural, economic and political factors (Reed, 2006). While it is not possible to explore all of the contributing factors in depth, we have selected those we considered key. We envisage that an exploration of the historical legal context will be helpful in practice, as often knowing what has gone before helps understand the current situation. In the next section, we will present a descriptive chronological overview of successive legislation and the key contributing factors that were pivotal to the establishment of that legislation.

\section{Mental health legislation in Aotearoa New Zealand}

In most countries, three forces work together to bring about social change. These comprise public opinion, the activities of voluntary and professional groups and the law. The law depends upon public opinion which, in turn, demands that the law acts in the public's best interest and that the public obey the law (Bilz \& Nadler, 2014). Reviewing a country's laws provides an understanding of public opinion when a law was developed: our focus is to highlight the tensions between social and occupational justice and the social control that the legislation attempts to create. As a colony of the British Empire, the laws of Aotearoa New Zealand were not created in a vacuum, but were firmly entrenched within British law, often at the peril of Te Tiriti's intent and the values and beliefs that underpin Te Ao Māori². Over time, mental health legislation has had a different focus - from protection of the public, dealing with those causing social problems, to an emphasis on consumer rights and services provided in a least restrictive environment. The review of the legislation in this article has been organised into these broad areas of focus.

\section{Focus on the protection of the public and "disposal" of people with a mental illness}

Early mental health legislation had a focus on the safe protection of the public from people that were considered to have a mental illness. The Lunatics Ordinance (1846) was the first mental health law enacted in Aotearoa New Zealand. This ordinance was based on societal expectations to provide for the safe custody and prevention of offences by persons who were regarded to be dangerously insane and for the care and maintenance of persons of unsound reasoning (Coleborne \& Mackinnon, 2006; Ernst, 1991). This legislative policy was firmly embedded in Georgian and early Victorian English values where religion had a stronghold and people with a mental illness were believed to be tainted by the devil. The Lunatic Ordinance was primarily concerned with the process of detaining dangerous people.

In 1868, new mental health legislation (the Lunatics Act, 1868) was deemed necessary due to the rapid development of regional asylums and the recommendation of the 1858 Select Committee for a revision of so-called lunacy laws (Brunton, 2005). The focus of the 1868 act was to provide legislation about the sites where people who were deemed to have mental health issues were housed and the care they were to receive whilst at these sites. This allowed for the setting up of licensed institutions (often private residences), legislate for medical 
management for all asylums; and drew a distinction between lunatics and lunatic patients (the latter referring to people already under care in an asylum). Essentially this act was aimed at greater regulation of what had been the ad hoc provision of care. The focus shifted away from the classification of what was termed "lunacy" towards procedures for confinement in an effort to ensure greater accountability and the more uniform provision of services (Campion, 2012). The changes of 1868 reflected societal demands and expectations and concerns for the plight of those with mental health issues.

Just over a decade later, in 1882, the Lunatics Act of 1882 was passed with the main thrust concentrating on public safety and the removal of dangerous people from the public arena to places of detention. The new act allowed for the detention of people described as "lunatics" based on evidence from family and friends when observation by designated professionals proved to be inconclusive in determining whether detention was indicated (Campion, 2012). The main drive for this act was to continue to make insanity a law and order issue where government had a central role (Campion, 2012). In 1908, the Lunatics Act came into force, which concentrated on the detention of people who were described as "dangerous lunatics." One significant change in this new legislation was the mention of treatment, implying that a mental health issue could be responsive to medical interventions, but this did not seem to be a legal requirement. This further reinforced Brunton's (2005) view that what was termed lunacy was seen as a law and order issue, rather than as a health condition that could respond to medical treatment or other interventions.

\section{Focus on those perceived to be causing social problems}

In the early 1900s, the Mental Defectives Act was passed and this was the first time the New Zealand Government articulated the difference between mental illness and mental disability (Ball, 2010). The Mental Defectives Act of 1911 seemed to be in response to pressure from medical and educational authorities who sought legislation to bring people who were described as "subnormal", under control. This change was influenced by the 1908 British Royal Commission on the Care and Control of the Feeble-minded (Hoult, 2007). The Royal Commission held the belief that people described as subnormal were responsible for many of society's problems such as alcoholism, prostitution, poverty and crime (Campion, 2012). The 1911 act also included provision for out-ofhospital compulsory care and gave health professionals a greater role in services beyond the hospital gate ( $\mathrm{O}^{\prime}$ Brien \& Kydd, 2013). There were several amendments to the Mental Defectives Act over the next forty years. In the 1914 Amendment, an alteration included a section about a person managing their own affairs; this acknowledged the societal shift towards the view that some service users were capable and therefore had the capacity to manage their own affairs. The Mental Defectives Amendment Act (1921) gave the Public Trustee the power to: take proceedings on behalf of "mentally defective patients," dissolve business partnerships of which mental health patients were members, and to administer property of mental health patients (New Zealand Legal Information Institute, 1921). The 1921 amendment assumed diminished capacity based on mental ill health and gave authority to the Public Trustee to make decisions on behalf of the person under the act.

During the period between World War One and World War Two there were changes in the way New Zealand society viewed the mentally unwell. This shift was in part due to the emergence of the eugenics movement. Eugenics was defined by Galton (1907) as "the study of the agencies under social control that may improve or impair racial quality of future generations either physically or mentally" (p. 17n). The eugenics movement influenced psychiatry 
where eugenicists argued that "measures such as sterilisation and institutionalisation of the mentally disabled as well as laws restricting immigration and marriage would improve public health" (Dowbiggin, 1997, p. vi). These notions influenced the 1928 amendment to the act where a Eugenics Board was established. The role of this board was to monitor people under the act and manage the resources required to oversee this group. The Eugenics Board also introduced a new category, titled the "social defective," where a person needed to be mentally deficient and involved in anti-social behaviour to come under the act. The societal view at the time was that the social defective needed supervision for their own and society's protection (Campion, 2012). In the Mental Defectives Amendment Act 1935, there were three main changes. Children were now included, in that minors could be admitted to institutions in the same manner as adults; secondly, that the Director General of Health could grant limited leave of absence to patients; and finally, that protection was given against civil or criminal liability to persons acting under authority of the act (New Zealand Legal Information Institute, 1935). A further amendment to the act in 1951 increased the power of the state in relation to escaped patients and transfer of patients between institutions (New Zealand Legal Information Institute, 1951). The legislation to this point was largely characterised by ideas of social control, aimed at those who were considered to be "undesirable" or not meeting society's expectations, and removing them from the public eye into institutions. The idea that those with mental health issues were a risk to public safety underpins the rationale for some of the legislation, emphasising the need for legislation that protected society. The legislation also reinforced society's view that those with mental health issues were not able to manage their own affairs, and needed to be taken care of. The legislation allowed the state to have a significant role in the provision and regulation of that care.

\section{Focus on mental health facilities and service delivery}

Between 1954 and 1961 there were five Mental Health Amendment Acts that were, in part, a response to public allegations that the government was neglecting mental health facilities and that mental health staff were abusing patients (Ball, 2010). As a result, amendments were made to the legislation which included the compulsory appointment of a suitably qualified doctor to a Medical Superintendent role in each establishment. In addition, it became compulsory for any establishment that housed over one hundred "mentally defective patients" to have a medical officer living in residence (Prebble, 2007). In 1969 the new Mental Health Act (1969) was introduced. This was during a period of rapid change in mental health care both locally and internationally (O'Brien \& Kydd, 2013). The purpose of the 1969 act was to substantially revise existing legislation (Ministry of Health, 1984). These revisions were responses to a Board of Health Committee Inquiry (1957-1960) that had foreseen the deinstitutionalisation of psychiatric hospitals. The Board of Health Committee recommended an increase in psychiatric services provided at general hospitals, an initiative that would reduce the reliance on institutions in the provision of mental health care (Brunton, 2005). The act also relaxed formalities surrounding the admission of informal patients to hospitals so as to align access to mental health services with entry procedures to general hospitals. In addition, provisions were introduced for regular reviews of each committed patient. Significantly, the Mental Health Act of 1969 was the first piece of legislation that had specific sections relating to both custody and treatment, thus making treatment legally binding (Ball, 2010).

\section{Focus on the balance between consumer rights and least restrictive intervention}

The New Zealand Bill of Rights Act 1990 was enacted to affirm, protect and promote 
human rights and fundamental freedoms in Aotearoa New Zealand. The act also affirmed Aotearoa New Zealand's commitment to the International Convention on Civil and Political Rights. When it was enacted, the Bill of Rights Act did not create any new rights but merely confirmed existing common law rights (New Zealand Ministry of Justice, 2013). However, the act did reiterate the following citizenship rights:

- not to be subjected to torture or cruel treatment (section 9);

- not to be subjected to medical or scientific experimentation (section 10);

- to refuse to undergo medical treatment (section 11);

- to be secure against unreasonable search and seizure (section 21);

- not to be arbitrarily arrested or detained (section 22).

While the Bill of Rights does protect New Zealanders' fundamental rights, it should be noted that these rights could be overturned by the Mental Health Compulsory Assessment and Treatment Act (1992) and the Mental Health (Compulsory Assessment and Treatment) Amendment Act (1999).

The Mental Health (Compulsory Assessment and Treatment) Act 1992 was a watershed piece of legislation as it entrenched the principles of compulsory assessment and treatment in the least restrictive environment (community care), in conjunction with patients' rights (Anderson, 2000). One of the key reasons behind the act was to reduce the association between criminal proceedings and inquiry into the mental state of patients, although it did lead to greater legal involvement in all aspects of the committal process (Bell \& Brookbanks, 1998). Legal involvement was aimed at ensuring patient rights including advocacy, and matters of informed consent were dealt with. The 1992 act also sought to elicit a greater range of opinions in making determinations about mental state than had occurred under previous legislation. For example, in section 16 of the act, decision-making is both a judicial and clinical procedure, with clinical opinions of other health professionals being considered in tandem with doctors who had traditionally been the sole decision makers. The act stipulated an initial period of compulsory assessment and treatment at the end of which a determination was made about whether the person was subject to a compulsory treatment order. During this period of compulsory assessment and treatment, the service user had a right to have his or her condition reviewed by a Family Court judge. Service users/tangata whaiora were permitted to seek this review on two occasions, either during the first period of assessment under section 11 or at a later date under section 13 (Fishwick, Tait, \& O'Brien, 2001). The act allowed for more checks and balances and review procedures to be established. These processes were aimed at protecting service users' rights and ensuring that unnecessary incarceration did not take place.

One of the consequences following the passing of the 1992 act, and to some extent facilitated by it, was a reduction in psychiatric hospital beds and the closure of stand-alone psychiatric hospitals. Although there were a number of other factors at play, including the rise of the consumer movement and the increased efficacy of drug treatments, the so-called Gibbs Report (Hospital and Related Services Taskforce, 1988) played a major role. The Gibbs Report advocated for closure of hospitals to reduce costs of government-provided services. In return this meant that options for long-term inpatient care became scarcer, and shorter periods of inpatient admission became more common. For those considered to need a longer period of compulsory care, the Community Treatment Order created the means of providing compulsory care in the community therefore meeting the policy and legislative requirements for care in a least restrictive environment (Bell \& Brookbanks, 2005). It is interesting to note that, as hospital numbers reduced, numbers of people under compulsory provisions remained much the same (O'Brien \& Kydd, 2013), indicating that the perceived need for compulsory assessment treatment remained static. 
The final piece of Aotearoa New Zealand's major mental health legislation which is still current, is the Mental Health (Compulsory Assessment and Treatment) Amendment Act 1999. The new act retained up to three assessment stages to the compulsory treatment order; a preliminary assessment, a five-day assessment and a 14-day assessment. The preliminary assessment is undertaken by a clinician, normally a psychiatrist. If this assessment finds there is reasonable proof of a mental health problem, then there could be further assessment and treatment for up to five days. Before the end of the five-day period the clinician must decide whether a patient has a mental disorder that requires further assessment or treatment. If this is the case, a patient can be held for further assessment and treatment for up to 14 days. By the end of this period the clinician decides whether a patient is well enough to be released (in which case no further compulsory treatment or assessment is given). If not, the clinician must apply for a compulsory treatment order under section 14. During the two initial assessment periods (the first for up to five days and the second for up to 14) patients can apply to have their compulsory assessment status reviewed by a Family Court or District Court judge (Gordon \& O'Brien, 2014). It has been argued by Newton-Howes and Ryan (2017) that compulsory treatment orders may be ineffective and force people with serious mental health symptoms to have treatment without consent and, as such, be a breach of their rights.

In the next section we will link the descriptive chronological review of the legislation to issues related to social and occupational justice and make suggestions for change informed by a social and occupational justice perspective.

\section{Discussion}

Since inception in 1848, New Zealand mental health legislation appears to be have shifted from a focus on the safety and protection of society in general to a focus on service user rights and care and treatment in a least restrictive environment. We suggest that there is a range of tensions that exist for practitioners and we believe that both social work and occupational therapy have a role in advocating for change to the practice and legislative framework. Ideally, the legal framework should be aligned with the recovery philosophy, which overarches New Zealand mental health service delivery. A recovery philosophy explicitly recognises service users' experiences of adversity, including compulsory detention and treatment. The recovery paradigm also champions mental health services to give greater recognition to the service user voice, even in situations of crisis where compulsory treatment might be considered. We agree with Gordon and O'Brien (2014) that current legislation "is antithetical to recovery because it implicitly suggests that people with mental illness pose such a degree of risk that this risk needs specific legislative recognition" (p. 59).

Statistics from the Office of the Director of Mental Health indicate the total number of people subject to both community and inpatient compulsory treatment is growing (Gordon \& O'Brien, 2014). Following an invitation from the New Zealand Government, the United Nations Working Group on Arbitrary Detention conducted a country visit in 2014. In their report, the Working Group highlighted that the Compulsory Assessment and Treatment Act 1992 is not effectively implemented to ensure that arbitrary deprivation of liberty does not occur. In practice, compulsory treatment orders are largely clinical decisions, and it is difficult to challenge such orders even though the Mental Health Act guarantees the right to legal advice for all patients. The Family Court, which makes compulsory treatment orders, does not specialise in mental health therefore relies heavily on medical reports completed by a psychiatrist and other medical professionals (United Nations Human Rights Commission, 2015). It appears that Aotearoa New Zealand's mental health legislation is in conflict with the 
philosophical approach taken by the United Nations. As Newton-Howes and Ryan (2017) highlighted, the use of compulsory treatment orders is out of step with current health practices and goes against the principles of recovery-oriented services. Their view is that it is the intervention that people receive rather than the treatment order that is most effective.

The tensions between complying with current statutory obligations, maintaining a therapeutic relationship and acting as an advocate for service users/tangata whaiora creates a difficult and often complex situation for practitioners. The role of the Duly Authorised Officer (DAO), for example, is a statutory role under the legislation and is sometimes performed by some social work and occupational therapy practitioners. The DAO role creates a power imbalance between the practitioner and client where the role under the act has the potential for conflict with a service user/tangata whaiora advocacy role, which is a similar tension faced by social work practitioners in child protection and youth justice contexts. In the current system social work and occupational therapy practitioners may be working with service users/tangata whaiora under community treatment orders. The power dynamics when therapeutically engaging with an individual under such an order in their own home has numerous complexities in building and maintaining an effective relationship. From an occupational justice perspective, further exploration is required on how compulsory assessment and treatment regimens may impact a person's rights to participate in occupations of their choice, maintain their usual routines and habits and experience meaningful occupation. We also suggest that there is a strong need to advocate for different approaches or alternatives to compulsory assessment and treatment that are culturally relevant. This is especially important in the context of the obligations of the Te Tiriti, Te Ao Māori and the over-representation of Māori and Pacific peoples in mental health services. The conflict between statutory obligations and maintaining a therapeutic relationship with a service user has been explored in social work (Gibbs, Dawson, \& Mullen, 2005) and nursing (Clearly, 2003). We were unable to find any literature that explored this issue in relation to occupational therapy.

There is potential for social work and occupational therapy practitioners to advocate for a least restrictive alternative to compulsory assessment and treatment orders that is more in line with recovery principles. This should include recognising the inherent potential in all people impacted by mental health issues and working together with them in all decision-making processes about their recovery journey. This could include promoting and protecting individual's legal, citizenship and human rights and supporting individuals to develop social, recreational, occupational, educational and vocational activities that are meaningful to them. This advocacy role has its challenges when the current framework is weighed heavily towards medico-legal concerns wherein medication and incarceration are the predominant interventions. The potential of recovery-focused social and/or occupational interventions needs to be promoted as being as effective, if not more so than compulsory treatment orders.

From a social work perspective, this would mean greater acknowledgment of social models of care which are focused on strengths, personal growth, quality of life, general well-being, and where the effects of mutual interactions of individuals are key. This would support an emphasis on the person-in-environment perspective (Saleeby, 1992), by focusing on addressing social justice issues related to equity and access to the necessities of life. This could include, as Khoury and Rodriguez del Barrio (2015) suggest, re-connecting the person to valuable resources in the community-friends, family, work, education, hobbies and peer support. This may mean the social work practitioner works with organisations or individuals to alter services to address access and equity of access to services so these 
services are more accommodating for those considering engaging in a recovery process with or without access to the mental health system. The social work practitioner could more regularly act as a social connector, encourager, advocate, system navigator, decision maker, support person or family/ whānau counsellor.

From an occupational justice perspective, there would be a greater focus on meaningful occupation and the personoccupation-environment perspective (Strong et al., 1999). Being able to engage in activities of choice is a social and occupational justice issue, a key role for occupational therapists and social workers is in identifying barriers (social, financial, attitudinal, etc.) to engagement and then reducing or removing those barriers. This would include, as Synovec (2015) encourages, the occupational therapist teaching and supporting the active use of coping strategies to help manage the effect of symptoms of illness. Creating opportunities for people to engage in activities that promote health and support a wellness lifestyle by addressing barriers and building on existing abilities would increase opportunities to engage in meaningful occupations is also a key role. This could include supporting the identification of personal values, needs, and goals to enable informed, empowered and realistic decision making, such as when considering housing, education and employment options. In concert, this would also involve addressing socio-political barriers that may impede participation in occupations where a person is unable to contribute to their community through education or employment because of factors beyond their control. Another area of focus could be on providing information to increase awareness of community-based resources, such as peer-facilitated groups and other support options. This would likely be a two-way process, working with these services to ensure that they reduce any barriers to increase ease of access for people with mental health issues. Finally, working in partnership with the individual and across agencies to support engagement in long- term planning related to work, education or housing would support a person to function as fully as possible in their community.

At a systems level, social work and occupational therapy practitioners could campaign for changes to the mental health legislation. This could include discouraging or ceasing the use of compulsory treatment orders and promoting the vital role of social and occupational justice in recoveryoriented services that are more focused on fair treatment of people with mental health issues. Ensuring that a person's human rights are not breached is a key concern for both professions. In relation to service delivery, there is a need to create change in relation to service expectations and reporting requirements. A stronger focus on recovery principles and on social and occupational needs will likely mean that service expectations related to the number of people seen in a day by a practitioner, time spent with an individual or the number of people on a caseload would need to change. This would require a shift from financial or output measures to measures focused on recovery, and social or occupational outcomes rather than broad service level outcomes. For practitioners, this would allow for increased flexibility; allow for an individual's needs to be met and increase professional autonomy to allow practitioners to develop relationships with individuals, family/whānau and communities and, in doing so, use a diversity of intervention approaches that can be co-designed by the service user and practitioner.

These broad -based suggestions, both at a practice and systems level create a challenge for occupational therapy and social work practitioners to see beyond practice as it is currently framed by dominant medico-legal views. Our suggestions call on practitioners to imbed their practice in the ideals of the recovery paradigm while developing their practice to alleviate social and occupational injustices across of the spectrum of mental health service delivery and associated legislation. 


\section{Conclusion}

The development of mental health legislation in Aotearoa New Zealand appears to have been strongly influenced by an English legal perspective at the expense of the obligations outlined in Te Tiriti or consideration of the principles of Te Ao Māori. Early legislation was focused primarily on ideas of social control with safety and protection of society at the forefront. In more recent years, legislation has focused on service user/tangata whaiora rights and treatment of people in a least restrictive environment, but this legislation is now nearly twenty years old. The dominance of the medico-legal worldview creates tensions for social workers and occupational therapy practitioners who are informed by thinking from social and occupational justice positions respectively. This tension creates a complex practice situation when trying to juggle statutorily obligations alongside developing a therapeutic relationship with a service user while also acting as an advocate and staying true to professional foundations. In providing a descriptive chronological review of New Zealand's mental health legislation, we identified some of the issues for social work and occupational therapy practitioners in the context of social and occupational justice. We call on social work and occupational therapy practitioners to promote change in the legislative and practice context to ensure that the vital role of social and occupational justice is used to challenge the dominance of the medico-legal worldview. Challenging the status quo would ensure that the ideals of recovery and social and occupational justice are embedded in legislation and service delivery while, in turn, ensuring that, care and treatment takes place in the least restrictive environment possible, and where alternatives to current interventions are considered to ensure that social and occupational justice issues are alleviated.

\section{References}

Anderson, M. (2000). A strain towards consensus? The individual, the family, and New Zealand's mental health (compulsory assessment and treatment) amendment bill 1999. Psychiatry, Psychology and Law, 7(1), 111-118. doi:10.1080/13218710009524976
Anthony, W. (1991). Recovery from mental illness. The new vision of the mental health system in the 1990s. Psychosocial Rehabilitation Journal. 16, 11-23. Retrieved from http://www.apa.org/pubs/journals/prj/

Ball, C. A. (2010). Mental health legislation in New Zealand since 1846 to date: A discourse analysis. (Unpublished master's thesis). Eastern Institute of Technology, Taradale, NZ. Retrieved from http://repository.digitalnz. org/system/uploads/record/attachment/646/mental_ health_legislation_in_new_zealand_from_1846_to date_a_discourse_analysis.pdf

Bell, S. A., \& Brookbanks, W. J. (1998). Mental health law in New Zealand. Wellington, New Zealand: Brookers.

Bell, S. A., \& Brookbanks, W. J. (2005). Mental health law in New Zealand. Wellington, New Zealand: Brookers.

Bernays, E. L. (1945). Public relations. Norman, OK: University of Oklahoma Press.

Bilz, K., \& Nadler, J. (2014), Law, moral attitudes, and behavioural change. In E. Zamir \& D. Teichman (Eds.), The Oxford handbook of behavioural economics and the law (pp. 247-267). Oxford, UK: Oxford University Press.

Brunton. W. (2005). The place of public inquiries in shaping New Zealand's national mental health policy 1858-1996 Australian and New Zealand Health Policy, 10(24). doi:10.1186/1743-8462-2-24

Campion, M. (2012). Mental health and legal landscapes. In C. Coleborne (Ed.), Changing times, changing places: From Tokanui Hospital to mental health services in the Waikato, 1910-2012 (pp. 13-26). Hamilton, New Zealand: Half Court Press.

Canadian Association of Occupational Therapists. (1997). Enabling occupation: An occupational therapy perspective. Ottawa, ON, Canada: CAOT Publications ACE.

Clearly, M. (2003). The challenges of mental health care reform for contemporary mental health nursing practice: Relationships, power and control. International Journal of Mental Health Nursing 12(2), 139-147. doi:10.1046/ j1440-0979.2003.00280x

Coleborne, C., \& Mackinnon, D. (2006). Psychiatry and its institutions in Australia and New Zealand: An overview. International Review of Psychiatry, 18(4), 371-380. doi/pdf/10.1080/09540260600813248

Deegan, P. (1988). Recovery: The lived experience of rehabilitation. Psychosocial Rehabilitation Journal, 11, 11-19. Retrieved from http://www.apa.org/pubs/journals/prj/

Dowbiggin, I. R. (1997). Keeping America sane: Psychiatry and eugenics in the United States and Canada, 1880-1940. Ithaca, NY: Cornell University Press.

Durocher, E., Rappolt, S., \& Gibson, B. E. (2014). Occupational justice: Future directions. Journal of Occupational Science 21(4), 431-442. doi:101.1080/ 14427591.2013.775693

Ernst, W. (1991). The social history of Pākehā psychiatry in nineteenth-century New Zealand: Main themes. In L. Bryder (Ed.), A healthy country: Essays on the social history of medicine in New Zealand. Wellington, New Zealand: Bridget Williams Books.

Fishwick, M., Tait, B., \& O’Brien, A. J. (2001). Unearthing the conflicts between carer and custodian: Implications of participation in Section 16 hearings under the Mental Health (Compulsory Assessment and Treatment) Act (1992). Australian and New Zealand Journal of Mental 
Health Nursing, 10, 187-194. doi:10.1046/j.14400979.2001.00209.x

Galton, F. (1907). Inquiries into human faculty and its development. New York, NY: Dutton.

Gibbs, A., Dawson, J., \& Mullen, R. (2005). Community treatment orders for people with serious mental illness: A New Zealand study. British Journal of Social Work, 1-16. doi:10.1093/bjsw/bch392

Gordon, S., \& O'Brien, A. (2014). New Zealand's mental health legislation needs reform to avoid discrimination. New Zealand Medical Journal, 127(1403), 55-65. Retrieved from https://www.nzma.org.nz/journal

Hamedi, A. (2014). The concept of justice in Greek philosophy (Plato and Aristotle). Mediterranean Journal of Social Sciences, 5(27), 1163-1167. doi:10.5901/ mjss.2014.v5n27.p1163

Hospital and Related Services Taskforce. (1988). Unshackling the hospitals: Report from the Hospital and Related Services Taskforce. Wellington, New Zealand: Author

Hoult. A. (2007). Institutional responses to mental deficiency in New Zealand, 1911-1935: Tokanui Mental Hospital (Unpublished master's thesis). The University of Waikato, Hamilton. Retrieved from http://researchcommons. waikato.ac.nz/bitstream/handle/10289/2412/thesis. pdf?sequence $=1$

Khoury, E., \& Rodriguez del Barrio, L. (2015). Recoverorientated mental practice: A social work perspective. British Journal of Social Work, 45, Supplement 1, i27-i44. doi:10.1093/bjsww/bcv092

McCranie, A. (2011). Recovery from mental illness: The roots, meanings, and implementations of a "new" services movement. In D. Pilgrim, A. Rogers, \& B. Pescosolido (Eds.), The SAGE handbook of mental health and illness (pp. 471-489). London: SAGE Publications.

Mental Health Commission. (2012). Blueprint II: Improving mental health and wellbeing for all New Zealanders: How things need to be. Wellington, New Zealand: Author.

Ministry of Health. (1984). Review of the Mental Health Act 1969: Discussion papers. Retrieved from http://www moh.govt.nz/notebook/nbbooks.nsf/0/23E0DEF68DF84 3CE4C2565D70018AA3F/\$file/review\%20of\%20the\%20 mental\%20health\%20act\%201969.pdf

Ministry of Health (2012). Rising to the challenge: The mental health and addiction services plan 2012-2017. Wellington, New Zealand: Author.

New Zealand Legal Information Institute. (1935). Mental Defectives Amendment Act 1935 (26 GEO V 1935 No 7). Retrieved from http://www.nzlii.org/nz/legis/hist_act/ mdaa193526gv1935n7320/

New Zealand Legal Information Institute. (1951). 1951 No 47 Mental Defectives Amendment. Retrieved from http://www.nzlii.org/nz/legis/hist_act/mdaa19511951n 47275.pdf

New Zealand Ministry of Justice. (2013). New Zealand Bill of Rights Act 1990. Retrieved from http://www.justice.govt. nz/policy/constitutional-law-and-human-rights/humanrights/domestic-human-rights-protection/about-thenew-zealand-bill-of-rights-act/copy_of_new-zealandbill-of-rights-act-1990

Newton-Howes, G., \& Ryan, C. (2017). The use of community treatment orders in competent patients is not justified.
British Journal of Psychiatry, 210, 311-312. doi:10.1192/ bjp.bp.116.193920

O'Brien, A. J., \& Kydd, R. (2013). Compulsory community care in New Zealand mental health legislation 1846-1992. SAGE Open. April-June. doi:10.1177/2158244013490175

Prebble, C. M. (2007). Ordinary men and uncommon women: A history of psychiatric nursing in New Zealand public mental hospitals, 1939-1972 (Unpublished doctoral dissertation). University of Auckland, New Zealand. Retrieved from https://researchspace.auckland.ac.nz/ handle/2292/1516

Rapp, C.A., \& Goscha, R.J. (2012). The strengths model: A recovery orientated approach to mental health services (3rd ed.). New York, NY: Oxford University Press.

Reed, K. (2006). The historical context of the blueprint for mental health services. New Zealand Journal of Occupational Therapy, 53(1), 5-9. Retrieved from https://www.otnz.co.nz/public/publications/new-zealandjournal-of-occupational-therapy/

Saleeby, D. (1992). Biology's challenge to social work: Embodying the person-in-environment perspective. Social Work, 37(2), 112-118. Retrieved from https://acadmeic.oup.com/sw

Stadnyk, R., Townsend, E., \& Wilcock, A. (2010). Occupational justice. In C. H. Christiansen \& E. A. Townsend. (Eds.), Introduction to the art and science of living ( $2^{\text {nd }}$ ed. pp 329-358). Upper Saddle River, NJ: Pearson Education.

Strong, S., Rigby, P., Stewart, D., Law, M., Letts, L., \& Cooper, B. (1999). Application of the personenvironment-occupation model: A practical application. Canadian Journal of Occupational Therapy, 66(3), 122-133. doi:10.1177/000841749906600304

Synovec, C. (2015). Implementing recovery model principles as part of occupational therapy in inpatient settings. Occupational Therapy in Mental Health, 31(1), 50-61. doi:10.1080/0164212X,2014.1001014

Te Pou. (2014). Competencies for the mental health and addictions service user, consumer and peer workforce. Auckland, New Zealand: Author.

United Nations Human Rights Commission. (2015). Statement at the conclusion of its visit to New Zealand (24 March-7 April 2014) by the United Nations Working Group on Arbitrary Detention. Retrieved from http://www. ohchr.org/EN/NewsEvents/Pages/DisplayNews.aspx? NewsID=14563\&LangID=E\#sthash.wdQHxTCw.dpuf

Wilcock, A., \& Townsend, E. (2000). Occupational terminology: Interactive dialogue. Journal of Occupational Science 7(2), 84-86. doi:10.1080/1442759 1.2000 .9686470

Wilcock, A. (2006). An occupational perspective of health ( $2^{\text {nd }}$ ed.). Thorofare, NJ: Slack.

\section{Notes}

${ }^{1}$ Te Tiriti ō Waitangi (Treaty of Waitangi) considered to be the founding document of New Zealand, signed in 1840 by representatives of the British Crown and various Māori (indigenous) chiefs.

2 Te Ao Māori is the Māori world and includes language, cultural processes and practices, sites of importance and connections to family and community. 